\title{
Cost performance dynamics in lean production leveling
}

\author{
Ahmed M. Deif ${ }^{a, *}$, Hoda ElMaraghy ${ }^{\mathrm{b}}$ \\ a Industrial and Service Engineering Department, Nile University, Cairo, Egypt \\ ${ }^{\mathrm{b}}$ Industrial and Manufacturing Systems Engineering Department, University of Windsor, ON, Canada
}

\begin{abstract}
A B S T R A C T
Balancing of production systems is one of the main lean manufacturing principles as it reduces in-process storage and related forms of waste. A dynamic systems approach is proposed to investigate challenges of implementing production leveling and associated costs. A lean cell producing at takt time is modeled using system dynamics. The model captures various lean tools influencing production leveling and their implications. Comparative cost analysis between various leveling implementation policies for stochastic demand with multiple products is conducted. Results showed that determining the most feasible leveling policy is highly dictated by both the cost and limitations of capacity scalability. In addition, delivery sequence plans of different products/parts needed to achieve mix leveling and lot sizes affect the feasible production leveling policy while implementing lean principles. The developed model and insights gained from the results can help lean manufacturing practitioners to better decide when and how to implement production leveling as well as determine both production lots sizes and sequence. They also emphasize the importance of cost analysis as assisting decision support tool in the trade-off required between the benefits of different levels of lean policies and their associated cost.
\end{abstract}

\section{Introduction}

Global competition, uncertain demand environment and higher consumer expectations are among many drivers for companies to adopt lean manufacturing principles and tools. Lean principle can be characterized in short by "doing more with less". This lean philosophy focuses on the elimination of waste and excess from the tactical product flows and represents an improvement and sometimes an alternative model to that of capital-intensive mass production with its large batch sizes, dedicated assets and hidden wastes. Lean manufacturing offers a wide set of lean mechanisms and tools to achieve these goals. They include, but are not limited to, kanban pulling cards, SMED (single minute exchange of dies), TPM (total productive maintenance), kaizen (continuous improvement) and Poke-yoke (mistake proofing). Successful implementation of these tools and principles would result in manufacturing systems characterized by having high-velocity order-to-delivery and flexible processes which improve the overall business performance.

Efficient production leveling in terms of volume and mix to eliminate over-production, is among the fundamental targets of lean manufacturing where over-production means producing more,

\footnotetext{
* Corresponding author.

E-mail address: deif@nileuniversity.edu.eg (A.M. Deif).
}

sooner or faster than is required by the next process [1]. Overproduction causes additional handling, inspecting, counting and storing costs of those not yet needed products. In addition, with over-production, defects remain hidden in the inventory queues until the downstream process finally uses the parts and quality issues are discovered. Heijunka is the Japanese term for load or production leveling which is the lean manufacturing strategy employed to eliminate over-production. Leveled production attains capacity balance and synchronization of all production operations over time in a manner that precisely and flexibly matches customer demand for the system's products. Ideally, this means producing every product in every shift in quantities equal to demand after smoothing out high frequency random components. Manufacturing processes should be operated at the takt time to achieve level production. The takt time is the target production frequency, based on the rate of sales, to meet customer requirements. Takt time synchronizes the pace of production with the pace of sales. Producing at takt time is achieved through means such as rapid machine setups/changeover, just in time flow and scalable capacity strategies.

In the current dynamic business context, leanness assessment has undergone, and is still undergoing, a process of continuous and never-ending evolution [2]. The assessment of leanness impact was usually related to performance metrics that focus on system productivity, cycle and/or lead times and quality improvements. Although previous metrics have direct and indirect impact on the 
system cost efficiency, more attention needs to be paid to the assessment of lean tools implementation and their associated costs and dynamic effects.

This paper proposes a dynamic systems approach to investigate the challenges of implementing production leveling, as one of the main lean principles, and assessing its associated costs and dynamic effects. After reviewing the related work on lean dynamic analysis and lean cost assessments, a dynamic model for a lean cell is presented. The model captures various lean tools for production leveling and their cost implications. A numerical analysis for stochastic demand with multiple products is conducted and insights concerning production leveling implementation and feasible implementation policies are presented.

\section{Literature review}

Extensive review about lean manufacturing definitions, their development and related research work can be found in [3-6]. In this section, particular focus is placed on related body of work which explores lean implementation dynamic modeling and analysis combined with lean implementation costing approaches.

Various research works focused on the general implementation of lean systems from dynamic perspective. Amin and Karim [7] proposed a time-based mathematical model for evaluating the perceived value of lean strategies to manufacturing waste reduction and a step-by-step methodology for selecting appropriate lean strategies to improve the manufacturing performance within their resource constraints. Cheah et al. [8] developed a hierarchal approach to study challenges and dynamics of implementing lean policies using interpretive structural method. They showed that some lean policies have higher risk of failure than others depending in the various system dynamics. Kodua et al. [9] investigated the dynamics of process design in lean systems implementation using a dynamic value stream mapping approach. They focused on how to change organizations decisions in accordance to product realization requirements using a dynamic modeling approach. Black [10] presented a group of qualitative and quantitative dynamic rules to implement lean manufacturing. The approach focused on how to make current mass production industrial operation leaner. Black presented nine different design rules to achieve such transformation. Cochran et al. [11] applied axiomatic design principles to design lean manufacturing systems with focus on line segmentation. They showed that integrating axiomatic design rules with lean management improved the design and performance of manufacturing systems. Detty and Yingling [12] demonstrated the use of discrete event simulation as a tool to assist organizations with the decision to implement lean manufacturing by quantifying the operational benefits achieved from applying lean principles. Other simulation studies were also conducted to investigate the impact of Just in Time (JIT) and Pull lean principles on improving manufacturing system operational performance [13,14]. Lian and Van Landeghem [15] combined simulation and value stream mapping together with existing data bases of production to develop a tool for assessing lean implementation. They introduced a model generator to compare the current and the future system, before and after lean implementation, based on improving the value stream. The comparison allows mangers to make better decisions on when, where and how to implement lean manufacturing from a value perspective. Discrete event simulation to examine impact of implementing both Lean and Green policies on overall system performance was used in [16]. They presented a case study which showed that when Lean and Green techniques are well tailored to the system using simulation, optimal system performance can result.

Specific implementation of production leveling (Heijunka) includes the early work of [17] who suggested a simple algorithm for Heijunka scheduling that has been used in practice. De Smet and Gelders [18] noted that implementation of Heijunka was only possible in situations where few schedule disturbances existed meaning that demand was relatively stable and predictable. The trade-off between Heijunka and system's responsiveness was also demonstrated by Ref. [19]. Using an automotive case study, Ref. [20] demonstrated the need to balance between Heijunka and the Just In Sequence approach if the customer requirements are dynamic in nature. Deif [21] suggested a dynamic capacity scalability mechanism that incorporates the accumulated backlog and WIP levels to better manage the trade-off between Heijunka and responsiveness.

Lean implementation costing analysis was reported for example by Ref. [22] who developed a dynamic cost of quality decision support system for lean systems. The system was used to guide management to establish a lean manufacturing oriented quality policy and control the incorporated costs effectively. Lopez and Arbos [23] provided evidence of possible mistakes of current transaction-based cost accounting techniques in lean systems and proposed value stream costing (VSC) based on the known VSM as a better approach for lean manufacturing costing. Same result were given by Meade et al. [24] who proved using simulation that classical accounting costing can hide improvements gained by lean implementation. Modarress et al. [25] presented a case study describing a method used to implement kaizen costing and provided incremental cost reduction activities to support lean production implementation. Unlike traditional systems which consider the accumulation of costs or time but not both, [26] used cost-time profile (CTP) as a tool to estimate cost-time investments (CTI) in an organization and measure its lean level. By focusing on cost and time, the proposed tool evaluated the impact of implementing lean tools and techniques on the manufacturing system performance.

Analysis of the previous research work reveals that dynamic analysis of lean implementation focused more on policies and decisions that would enhance the system design and/or the operational performance with less attention paid to the cost implications associated with these policies and decisions. This was demonstrated in the case of production leveling (Heijunka) implementation where most of the work focused on the trade-off between system's leveling and responsiveness. Finally, few research articles on lean costing were concerned mainly with exploring the optimal costing approach for lean implementation assessment.

The work presented in this paper responds to the need for dynamic analysis of lean implementation costing, especially Heijunka policies. A system dynamics model that incorporates both Heijunka techniques as well as its associated costs is presented along with analysis of lean implementation costing.

\section{Modeling production leveling in a lean cell}

The system dynamics model for a lean manufacturing cell by Deif [21] is adopted and modified to incorporate production leveling mechanisms as well as their associated lean costs. The new model is shown in Fig. 1. The displayed system is composed of a demand component that captures the stochastic nature of the demand and translates it to takt time and pull rate. The production component is modeled as a lean cell with three production centers or stations. The production is controlled by a pull rate which is a function of takt time and is affected by the availability of materials via the JIT mechanism. The production leveling is maintained through a sequencing policy which impacts the change-over time and also through a scalable capacity component. The backlog of the developed cell is monitored as well as the accumulated WIP and both account for what is called the "Producer Cost". In addition, the cost of implementing each of the adopted lean tools (SMED, 


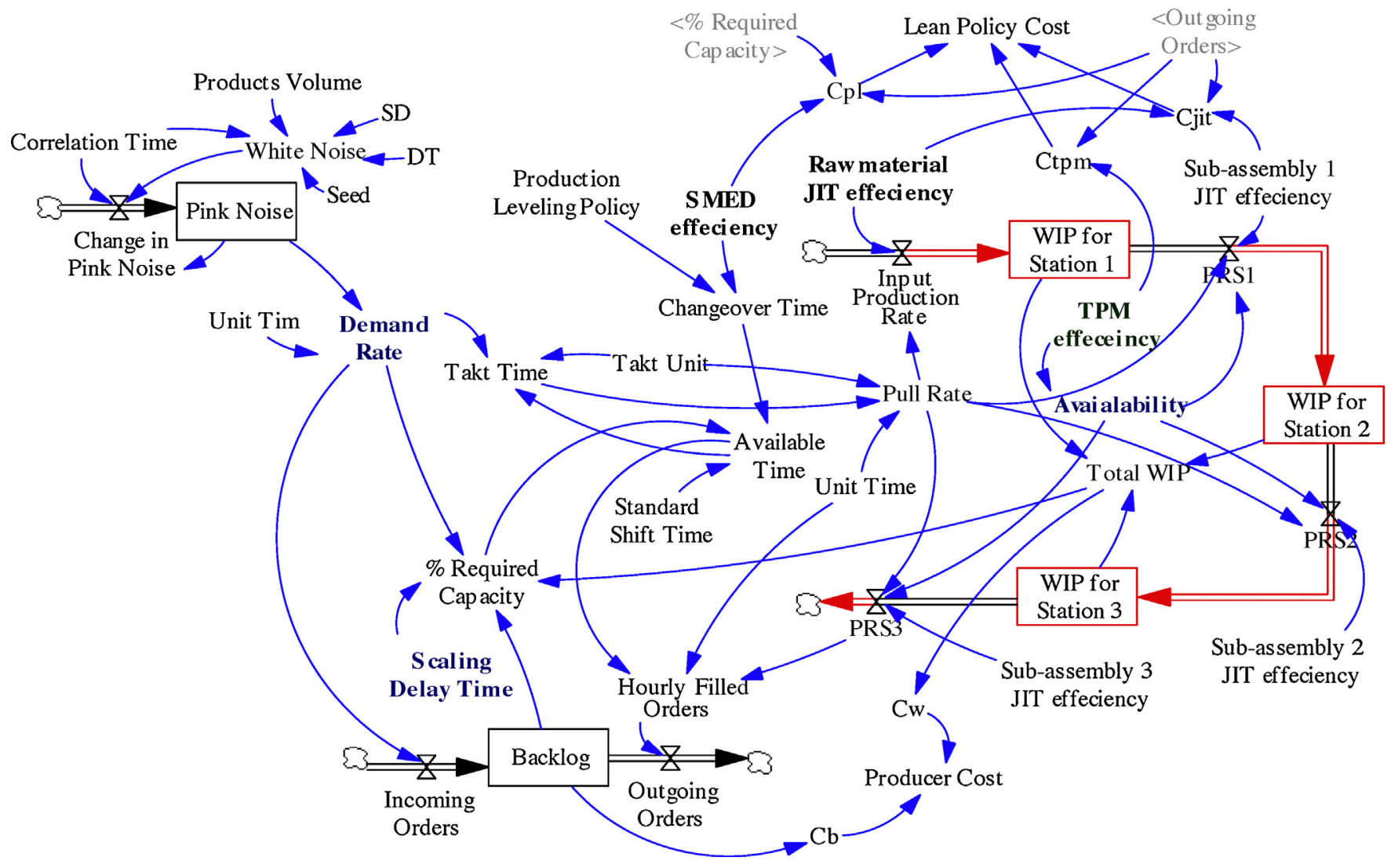

Fig. 1. Cost dynamics in a scalable lean manufacturing cell.

JIT, TPM and scalable capacity) is incorporated for different policies using activity based costing $(A B C)$ methodology. Each of these system components and their interactions are discussed in detail in this section.

\subsection{Model notations}

$B(t)=$ the backlog level at time $t$.

$\mathrm{WIP}_{i}(t)=$ the WIP level at time $t$ at station $i$.

$\operatorname{IPR}(t)=$ the input production rate.

$\operatorname{PR}(t)=$ the pull rate.

$\operatorname{PSR}(t)=$ the production start rate at time $t$.

$\mathrm{AD}(t)=$ the average demand at time $t$.

$\mathrm{CT}=$ the correlation time. It captures the degree of inertia in the noise process.

$\mathrm{SD}=$ the standard deviation for the normal demand distribution.

DT $=$ the time step.

Seed $=$ the seed for randomly generated variates of the stochastic demand data.

Avab. $=$ the system availability .

$\mathrm{IO}(t)=$ the incoming orders at time $t$.

$\mathrm{OO}(t)=$ the outgoing orders at time $t$. It is the rate of physical product leaving the cell.

$\operatorname{TWIP}(t)=$ the total WIP of the system at time $t$.

$\operatorname{HFO}(t)=$ the hourly filled orders at time $t$.

$\mathrm{AT}=$ the manufacturing available time.

$\mathrm{TT}=$ the takt time. It is the time that set the production pace.

$\% \mathrm{RC}(t)=$ the percentage of the required capacity to be scaled at time $t$.

$\mathrm{SDT}=$ the scalability delay time. Time require to scale the capacity. SST $=$ the standard shift time.

$C_{\mathrm{b}}(t)=$ cost of backlog (late penalty and loss of good will) at time $t$.
$C_{\mathrm{W}}(t)=$ cost of managing accumulated WIP at time $t$.

$C_{\mathrm{pl}}(t)=$ cost of production leveling (volume and mix) at time $t$.

$C_{\mathrm{tpm}}(t)=$ cost of total production maintenance at time $t$.

$C_{\mathrm{jit}}(t)=$ cost of JIT implementation at time $t$.

$C_{\mathrm{WIP}}(t)=$ cost of WIP management at time $t$.

$C_{\mathrm{Blg}}(t)=$ cost of backlog penalty at time $t$.

$C_{\text {Total }}(t)=$ total cost of production leveling at time $t$.

ACPR $=$ activity cost pool rate.

$P_{\mathrm{Blg}}=$ penalty cost for backlog.

$P_{\text {mix }}=$ penalty cost for mix leveling delay.

LPC $(t)=$ lean policy cost at time $t$. Costs associated with implementing lean tools.

$\mathrm{PC}(t)=$ producer cost incurred due to accumulated backlog and WIP at time $t$.

$\mathrm{TC}(t)=$ total cost of implementing production leveling policy at time $t$.

$\mathrm{CO}=$ change-over time.

$\mathrm{CO}_{\text {std }}=$ standard time for each change-over.

RMJIT $_{\text {eff }}=$ raw material JIT efficiency.

$\mathrm{SAJIT}_{\text {eff }}=$ sub-assembly JIT efficiency .

$\mathrm{TPM}_{\mathrm{eff}}=$ total productive maintenance efficiency.

MLS = mix leveling sequence.

\subsection{Dynamics of lean manufacturing cell with production leveling}

\subsubsection{Stochastic market demand}

The market demand is modeled as a stochastic parameter with dependent distribution or pink noise as referred to in the system dynamics literature [27]. In order to have a better abstraction of demand uncertainty it is necessary to model demand forecast as a process with memory in which the next value of demand is not dependent of the last but rather on the history of previous 
forecasts or pink noise. Pink noise, which is different from white noise, assumes that the variation of the demand is related to all previous demand data in a proportional logarithmic relation. The demand in this model is assumed to have a continuous cumulative normal distribution function. Huh et al. [28] state that demand should have a continuous distribution because demand is inherently continuous. Eq. (1) formulates the demand as white noise with a normal distribution.

White Noise $(t)=\mathrm{AD}(t)+\left[\mathrm{SD}^{2} * \frac{(2-(\mathrm{DT} / \mathrm{CT}))}{(\mathrm{DT} / \mathrm{CT})}\right]^{0.5}$

$$
* \operatorname{Normal}(0,1, \text { Seed })
$$

Eqs. (2) and (3) display the values for the demand pink noise and the change in demand pink noise, respectively

Pink Noise $(t)=$ Change in Pink Noise - Pink Noise ${ }_{0}$

Change in Pink Noise $=\frac{\operatorname{Pink} \text { Noise }(t)-\text { White Noise }(t)}{\text { CT }}$

The demand rate (DR) is calculated by dividing the change is pink noise by the manufacturing unit time as in Eq. (4):

$\mathrm{DR}(t)=\frac{\text { Change in Pink Noise }}{\text { Unit time }}$

\subsubsection{Takt time and volume-mix production leveling}

Takt time (TT) is how often the manufacturer should produce one part based on the rate of sales to meet customer requirement. Takt time is calculated by dividing the customer daily demand into the available working time per day. Takt time is calculated as shown in Eq. (5):

$\mathrm{TT}=\frac{\mathrm{AT}}{\mathrm{DR}(t)}$

The available time is traditionally equal to the standard shift time of the factory multiplied by the number of shifts. However, in this model the lean cell is augmented with dynamic capacity scaling mechanism as explained in the next paragraph. Thus, the available time is calculated as function of the standard shift time plus additional hours based on scaled capacity if needed. This extra available time is introduced to the modeled lean cell to maintain production-volume leveling. Practical examples for such dynamic capacity scaling can be through adding partial or full working shifts or a machine to the cell. Furthermore, the production-mix leveling is introduced through a mix policy dictated by the customer. The mix policy is reflected in the model through changeover time (CO). The changeover time is calculated based on the number of changeovers multiplied by the changeover standard time (the time required to switch from one product to the other) as expressed in Eq. (6). For example, if the system is required to produce two products ( $A$ and $B$ ) each for 20 parts per month, then a mix leveling policy of producing 20 parts of $A$ then 20 parts of $B$ will have the number of changeovers equals 2 (one at the end of each batch) while the mix leveling policy of producing $10 \mathrm{~A}$ then $10 \mathrm{~B}$ and then $10 \mathrm{~A}$ and $10 \mathrm{~B}$ will have the number of changeovers is 4 . The time for changeover is subtracted from the available time which is thus calculated is shown in Eq. (7):

$\mathrm{CO}=$ Production Leveling Policy $* \mathrm{CO}_{\text {std }}$

$\mathrm{AT}=\mathrm{SST}(1+\% \mathrm{RC})-\mathrm{CO}$

\subsubsection{Dynamic capacity modeling}

The use of dynamic capacity techniques is more common with today's new manufacturing paradigms of changeable, reconfigurable and flexible systems $[29,30]$. However, dynamic scalability policies are more challenging. In other words, if scaling capacity is feasible, how can the best magnitude of capacity change be determined? In this paper a hybrid scaling policy is adopted from [21]. The hybrid capacity policy considers the demand rate, the current system's work in progress (WIP) level and the system's backlog when deciding on the capacity scaling value. The capacity scaling value aims at maintaining leveled production volume. This integrated policy is believed to improve the system overall responsiveness as it accounts for external as well as internal uncertainties. The required capacity based on the hybrid policy is shown in Eq. (8). It is important to note that a scaling delay time is modeled since practically speaking; instantaneous capacity scaling is not feasible in the manufacturing context.

$\% \mathrm{RC}(t)=\left[\frac{\mathrm{TWIP}(t)+\operatorname{Backlog}(t)}{\mathrm{SDT}}\right] / \mathrm{DR}$

\subsubsection{Production control}

The WIP level at each station in the lean cell shown in Fig. 1 is determined by the difference between the production rate of the current station and the production rate of the next one (Eq. (9)).

$\mathrm{WIP}_{i}(t)=\mathrm{PRS}_{i}(t)-\mathrm{PRS}_{i+1}(t)$

To demonstrate the pull dynamics of the modeled lean manufacturing cell, the production rate is set to be equal to a pull rate calculated based on takt time. In addition, the pull rate at each manufacturing stage is also determined based on machine availability of each stage as well as the readiness of materials and sub-assemblies required for each stage. In order to illustrate the role of lean tools in maintaining successful production leveling policies, the availability of machines can be increased by applying total productive maintenance (TPM) which is referred to in this model as TPM efficiency. Furthermore, the readiness of materials and sub-assemblies can increase by applying JIT techniques (like kanban cards and supermarkets) which are referred to in this model as JIT efficiency. Both types of efficiency increase the production rate, which in turn can better level the production. The availability of each stage is stochastically modeled as a random uniform distribution. The previous production dynamics are shown in Eqs. (10)-(12).

$\operatorname{PR}(t)=\left(\frac{\mathrm{TT}}{\text { Unit Time }}\right) *$ Takt Unit

Note that unit time and takt units are parameters with value of one and are used to keep dimensional (units) balance. Also in Eq. (11), the input production rate is equal to the pull rate and no over-capacity is considered as this reflects the traditional practice of lean pull systems.

$\operatorname{IPR}(t)=\operatorname{PR}(t) * \operatorname{JIT}_{\text {eff }_{i}}$

$\mathrm{PRS}_{i}(t)=\mathrm{PR}(t) * \mathrm{JIT}_{\mathrm{eff}_{i}} * \mathrm{Avab}_{i} * \mathrm{TPM}_{\mathrm{eff}}$

\subsubsection{Backlog calculation}

The backlog level is calculated as the difference between the input order rate, which is assumed to be exactly equal to the hourly demand rate as expressed in Eq. (4) and outgoing order rate. The outgoing order rate is a function in hourly filled orders based on both the production rate of the lean cell which is controlled by the last station's rate and the available time. Backlog calculations are expressed in Eqs. (13)-(16).

$B(t)=\mathrm{OO}(t)-\mathrm{IO}(t)$

$\mathrm{IO}(t)=\mathrm{DR}(t)$

$\mathrm{OO}(t)=\mathrm{HFO}(t)$

$\mathrm{HFO}(t)=\operatorname{PRS} 3(t) * \mathrm{AT}$ 


\subsection{Production leveling implementation cost}

Studying the feasibility of applying production leveling lean policies requires calculation of two types of cost. The first is the cost associated with lean tools used to assist in successful implementation of production leveling - in this paper they are referred to as lean policy cost. The second is the cost incurred due to managing the accumulated WIP and cost due to backlog referred to as producer cost. The cost structure used to calculate the production leveling cost is similar to the concept of Activity-Based Cost (ABC) introduced by [31]. Activity-Based Costing is considered by many researchers to be more suitable for lean costing than the traditional transaction-based costing systems $[22,32,33]$. Activity-Based Costing estimates the product/service cost by assigning cost to the activities involved in their creation process. These activities can be distributed among elements of the proposed model: (1) produced units as is the case for JIT and TPM, (2) batch as is the case for SMED, (3) process as is the case for scaled capacity, and facilitylevel homogenous cost pools. In managerial accounting; activity cost pool is a set of costs incurred when certain operations are performed within the organization. By accounting for all costs incurred in a specific activity within a pool, it becomes simpler to assign those costs to products and obtain an accurate estimate of production costs. Activity cost pool is an aggregate of all the costs required to perform a lean production task. The detailed calculation of each of the considered activity cost pooling rate is not considered in this research as the impact of various lean policies on production leveling implementation feasibility is the main focus.

\subsubsection{Lean policy cost}

The first cost is the cost associated with implementation of JIT activity. The objective of implementing JIT in this model is to contribute to effective production leveling by ensuring that the required raw materials and subassemblies upstream and through production stages are available when needed and as needed. In order for JIT mechanisms to succeed in achieving their objective and to speed up the pull rate in the system, efforts should be made to reduce variability in the system, maintain high level of synchronization with suppliers, dedicate resources for pull/kanban system and finally perform flexible cross training. The cost of these activities is distributed over the produced units through the JIT cost pool rate as shown in Eq. (17).

$$
C_{\mathrm{JIT}}(t)=\left(\mathrm{RMJIT}_{\mathrm{eff}} * \mathrm{ACPR}_{\mathrm{RMJIT}}+n\left(\mathrm{SAJIT}_{\mathrm{eff}} * \mathrm{ACPR}_{\mathrm{SAJIT}}\right)\right) * \mathrm{OO}(t),
$$

where $n:$ no. of stages

The second cost considered to maintain successful leveling implementation is the cost of applying TPM to increase machines' availability. Increasing the availability of the production stages will enhance pull rate and contributes to efficient JIT implementation. TPM cost usually reflects the effort and resources dedicated for maintenance, training and associated tools. TPM cost is distributed over produced units through the TPM cost pool rate as shown in Eq. (18).

$C_{\mathrm{TPM}}(t)=\mathrm{TPM}_{\mathrm{eff}} * \mathrm{ACPR}_{\mathrm{TPM}} * \mathrm{OO}(t)$

The final cost considered in this category is the cost incurred for volume and mix leveling. A dynamic capacity approach is used to maintain volume levels by scaling up available production time as mentioned earlier. The cost of such scaling captures the required effort, time delays as well as the used resources secured such as extra shifts or machines. In this model the capacity scaling cost is distributed over process cost pool rate for each required scaling unit. Product mix leveling is achieved through a policy based on customer's definition of delivery sequence. Better responsiveness in manufacturing requires smaller batch sizes of the multiple produced products; however, this comes with associated additional cost. The cost for mix leveling is a function of the number of setups required to maintain the required mix leveling sequence. An activity cost pool rate is used at the batch level to account for the time, effort and resources required for the changeover activities of the selected sequencing. The total cost for both volume and mix leveling is shown in Eq. (19).

$C_{\mathrm{PL}}(t)=\% \mathrm{RC}(t) * \mathrm{ACPR}_{\mathrm{Cap}}+\mathrm{MLS} * \mathrm{ACPR}_{\mathrm{mix}}$

The overall lean policy cost is simply the summation of the previous three lean implementation costs as shown in Eq. (20).

$\mathrm{LPC}(t)=C_{\mathrm{JIT}}+C_{\mathrm{TPM}}+C_{\mathrm{PL}}$

\subsubsection{Producer cost}

The producer cost in this model refers to the cost of accumulated WIP and backlog orders. The WIP cost is mainly due to the time and effort required to manage and reduce WIP such as extra material handling activities, temporary buffers and production re-planning. It is distributed over produced units through WIP cost pool rate as shown in Eq. (21).

$C_{\mathrm{WIP}}(t)=\operatorname{TWIP}(t) * \mathrm{ACPR}_{\mathrm{WIP}}$

The backlog cost is a penalty paid by the system for inefficient responsiveness level (i.e. defaulting on due dates) as well as the loss of the good will of the customers. It is always challenging to quantify the later component of the backlog cost, but for simplicity in this model they are both aggregated into one cost as shown in Eq. (22).

$C_{\mathrm{Blg}}(t)=\operatorname{Backlog}(t) * P_{\mathrm{Blg}}$

The total producer cost is shown in Eq. (23) while the overall production leveling implementation cost is expressed in Eq. (24).

$\mathrm{PC}(t)=C_{\mathrm{WIP}}(t)+C_{\mathrm{Blg}}(t)$

$\mathrm{TC}(t)=\mathrm{LPC}(t)+\mathrm{PC}(t)$

\section{Investigating production leveling feasibility in dynamic lean cells}

The feasibility of various lean policies for implementing production leveling in the proposed lean cell is investigated. A case study for a lean cell assembling consumer electronics products is adopted from Detty and Yingling [12] to demonstrate the impact of three different lean polices on the cost of production leveling implementation. Additional data about lean policies and their associated costs is introduced based on experts' opinions in lean implementation in the consumer electronics products assembly field.

The facility is composed of six identical lean cells with only four planned for production and the other two represent capacity scalability options to increase production volume. Without losing generality and for simplicity, production dynamics of the identical cells are aggregated into one representative cell. The system is designed to produce a part family of 11 products. In this study only two products in this family are considered. The production process in each cell is carried out in three stations. Station one is dedicated for assembly and includes 12 sequential steps, station two is responsible for both inspection and testing in 4 steps and finally station three is for packing in 2 steps. Each station in the cell is supplied with parts from 2 parts storage areas and 2 satellite subassembly areas. Shipments are scheduled every two weeks. All analyses are carried out over a one month period $(160 \mathrm{~h})$. Data for the production system's base case scenario is listed in Table 1. A schematic diagram for considered case study is shown in Fig. 2. 


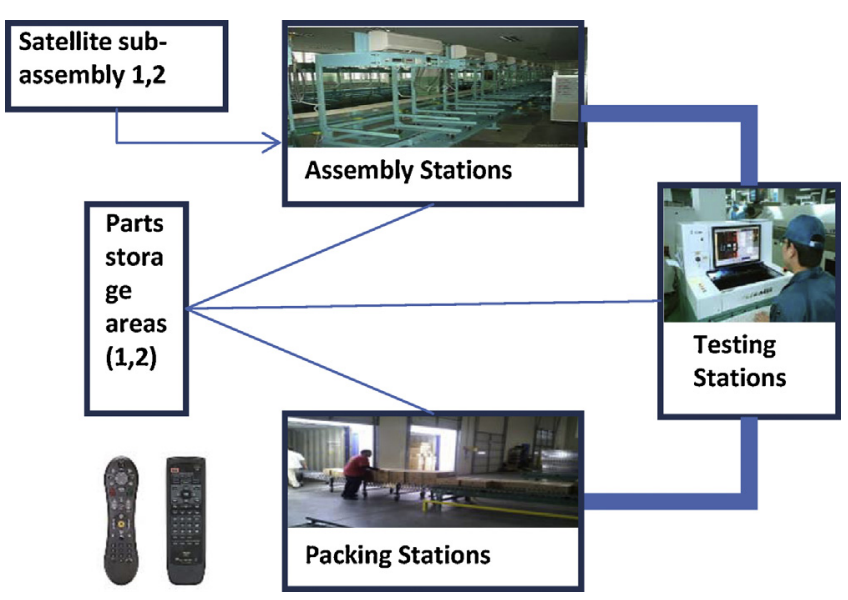

Fig. 2. Lean cell assembling consumer electronics products.

A lean policy in this paper refers to a group of lean tools implemented to attain production leveling. Each lean policy has an expected improvement level in some system's aspects based on the degree to which each tool is implemented. The three lean policies considered for implementation in this study are "best lean policy" which represents the maximum improvements level the considered system can reach, "average lean policy" representing an average improvements level and finally "no lean policy" where the system is performing in its current state without any improvements. Table 2 displays the detailed improvements due to implementing each policy and the associated activity cost pool rate (ACPR) costs of implementing each lean tool within that policy.

Table 1

Input for base case scenario data.

\begin{tabular}{ll}
\hline Parameter & Value \\
\hline $\begin{array}{l}\text { Stochastic demand rate (mean } \\
\text { and standard deviation) }\end{array}$ & 60 parts $/ \mathrm{h}, 12$ parts $/ \mathrm{h}(20 \%)$ \\
Number of parts & 2 parts $(30 \mathrm{parts} / \mathrm{h}$ each) \\
Standard shift time & $8 \mathrm{~h} /$ day, $40 \mathrm{~h} / \mathrm{week}, 160 \mathrm{~h} / \mathrm{month}$ \\
Station 1 availability & $95 \%$ \\
Station 2 availability & $93 \%$ \\
Station 3 availability & $91 \%$ \\
Scaling delay time & $1 \mathrm{~h}$ \\
Change over time & $0.2 \mathrm{~h}$ \\
Backlog penalty & $\$ 0.05 /$ part \\
Mix delay penalty & $\$ 0.01 / \mathrm{h}$ \\
WIP management cost & $\$ 0.01 /$ part \\
Capacity scaling cost $\left(\mathrm{ACPR}_{\text {cap }}\right)$ & $\$ 5 / \mathrm{h}$ for capacity percent increase \\
Product selling price & $\$ 30$ \\
\hline
\end{tabular}

\subsection{Impact of capacity scaling cost on feasibility of volume production leveling implementation}

The first scenario is concerned with the impact of capacity scaling cost on the total cost for lean production leveling implementation. The capacity scalability is an instrumental mechanism in maintaining production volume levels. In this case study, capacity scaling is achieved by utilizing the shut down production cells or adding extra shifts which increases available time and thus reduces takt time and increases productivity. Fig. 3 displays the overall total cost of the three considered lean policies at various capacity scalability costs. The scaling activities cost are pooled into the $\mathrm{ACPR}_{\text {cap }}$ which for the sake of analysis will range from as low as one dollar for every extra scaling percentage to ten dollars for the cost of the same unit depending on the different hourly rates in different shifts as well as the complexity of scaling and ramp up activities of the shut down cells. Analysis of the results reveals the following observations:

- For the three considered capacity scalability costs, there is a point during production time where the cost performance is switched between no lean and best lean policies while average lean policy prevails for very short time. This point is referred to as cost reversal point (CRP).

- CRP location on the production time axis is sensitive to the cost of capacity scalability. Practically, since the production time in this analysis reflects the production volume, thus depending on the scaling cost and the location of CRP, the planners can decide on the best batch size within each lean policy.

- In general, for short production periods and with the considered production settings, the no lean policy is more cost effective, while as production periods increase, the best lean policy becomes less costly to use. Among the reasons for such a dynamic behavior is the positive impact of production leveling on WIP and backlog reduction that cannot be manifested in short production runs.

- If capacity scaling can be kept at low level, then some lean polices from the considered cost perspectives are not clearly justified. However, since practically capacity scaling and thus production leveling usually come at considerable cost, lean policies are clearly important to reduce such cost.

\subsection{Impact of capacity scaling limit on volume production leveling implementation cost}

After exploring the impact of capacity scaling cost on production leveling feasibility, the impact of capacity scaling limit is investigated. Fig. 4 displays the overall total cost of implementing the three considered lean policies at various capacity scalability limits. The first limit is for the case where the two shut down cells are considered available and thus scaling the capacity up by $50 \%$. The second

Table 2

Lean policies data.

\begin{tabular}{|c|c|c|c|c|c|c|}
\hline \multirow[t]{2}{*}{ Lean policy } & \multicolumn{3}{|l|}{ Lean tools impact } & \multicolumn{3}{|l|}{$\operatorname{ACPR}(\$)$} \\
\hline & SMED & TPM & JIT & SMED & TPM & JIT \\
\hline Best lean & $\begin{array}{l}10 \% \text { reduction in } \\
\text { change over time }\end{array}$ & $\begin{array}{l}10 \% \\
\text { improvement } \\
\text { in availability }\end{array}$ & $\begin{array}{l}\text { Improves incoming raw material JIT } \\
\text { efficiency to be } 99 \% \text { and sub-assembly } \\
\text { JIT to be } 99 \% \text { in each station }\end{array}$ & $\$ 10 /$ batch & $\$ 0.2 /$ part & $\begin{array}{l}\$ 0.45 / \text { part (in-coming JIT) } \\
\$ 0.12 / \text { part (sub-assembly JIT) }\end{array}$ \\
\hline Average lean & $\begin{array}{l}5 \% \text { reduction in } \mathrm{c} / \mathrm{o} \\
\text { time }\end{array}$ & $\begin{array}{l}5 \% \\
\text { improvement } \\
\text { in availability }\end{array}$ & $\begin{array}{l}\text { Improves incoming raw material JIT } \\
\text { efficiency to be } 95 \% \text { and sub-assembly } \\
\text { JIT to be } 95 \% \text { in each station }\end{array}$ & $\$ 5 /$ batch & $\$ 0.1 /$ part & $\begin{array}{l}\$ 0.3 / \text { part (in-coming JIT) } \\
\$ 0.07 / \text { part (sub-assembly JIT) }\end{array}$ \\
\hline No lean & $\begin{array}{l}\text { No reduction in } \mathrm{c} / \mathrm{o} \\
\text { time }\end{array}$ & $\begin{array}{l}\text { No } \\
\text { improvement } \\
\text { in availability }\end{array}$ & $\begin{array}{l}\text { No improvements to basic JIT } \\
\text { efficiency: } 90 \%\end{array}$ & $\mathrm{~N} / \mathrm{A}$ & $\mathrm{N} / \mathrm{A}$ & $\mathrm{N} / \mathrm{A}$ \\
\hline
\end{tabular}



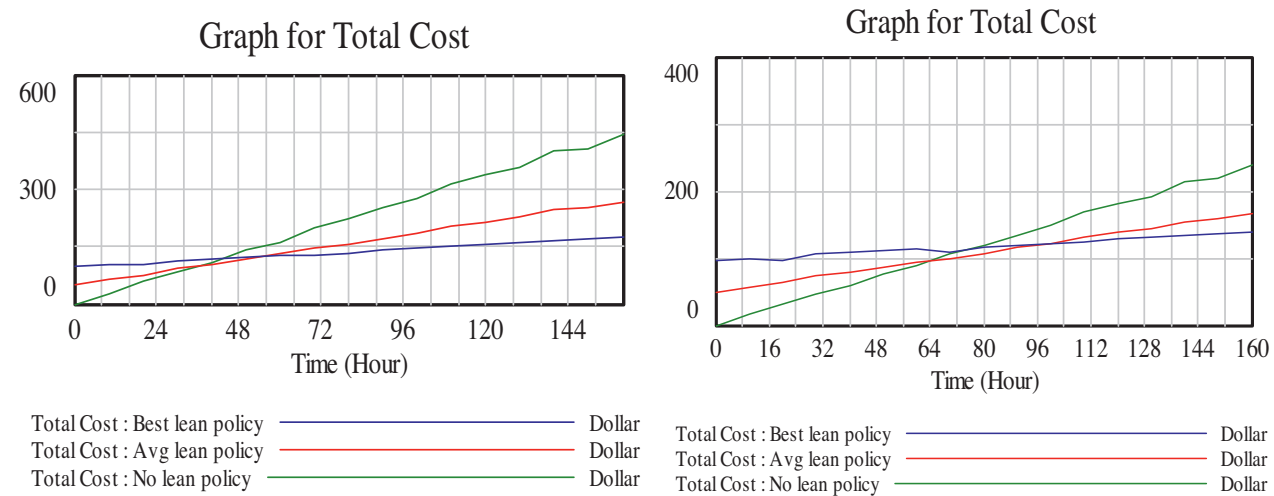

(a)

Graph for Total Cost

(b)

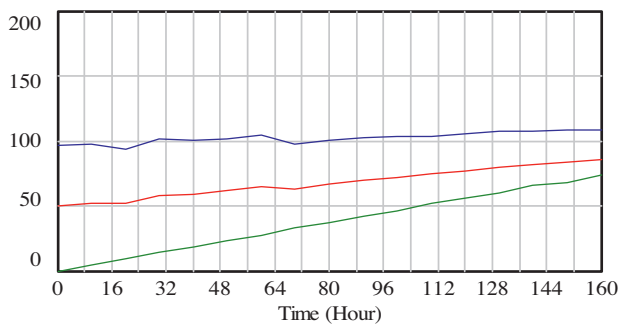

$\begin{array}{ll}\text { Total Cost : Best lean policy } & \text { Dollar } \\ \text { Total Cost : Avg lean policy } & \text { Dollar }\end{array}$

Total Cost : No lean policy

(c)

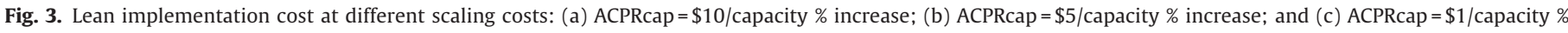
increase.

\section{Graph for Total Cost}

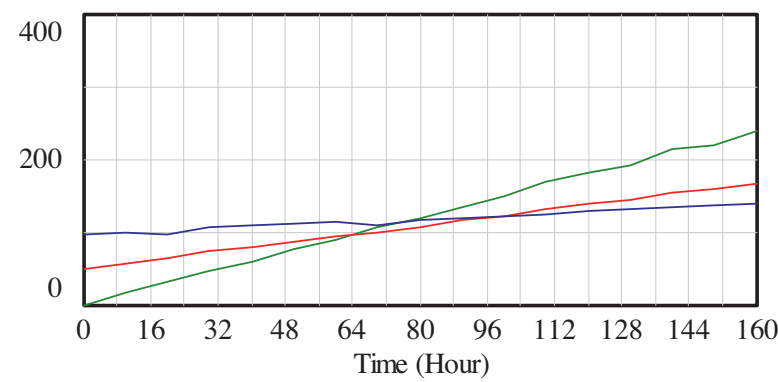

Total Cost : Best lean policy

Total Cost : Avg lean policy

Total Cost : No lean policy

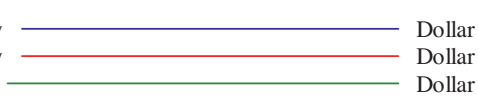

(a)

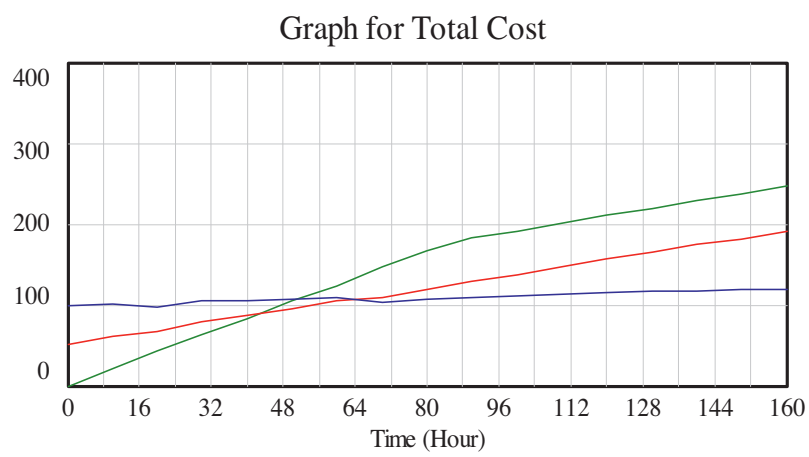

Total Cost : Best lean policy w limited cap

Total Cost : Avg lean policy w limited cap

Total Cost : No lean policy w limited cap

(b)

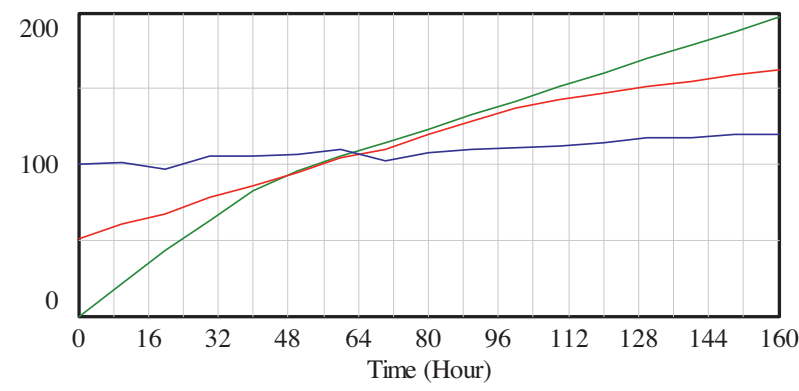

Graph for Total Cost

Total Cost : Best lean policy w limited cap

Total Cost : Avg lean policy w limited cap

Total Cost : No lean policy w limited cap

(c)

Fig. 4. Lean implementation cost at scaling limit of (a) $50 \%$ of available capacity, (b) $25 \%$ of available capacity, and (c) $12.5 \%$ of available capacity. 
case is where only one of these two cells is used and thus scaling the capacity up by $25 \%$. The last case is when only one of the four running cells works for an extra half shift scaling the capacity up by $12.5 \%$.

Limitation on capacity scaling is usually due to availability of machines or workers, feasibility of system's configuration changes or physical constraints such as space [34]. These limitations were introduced to the scaling unit in the model by choosing the minimum of required capacity percentage (\%RC) and the introduced scaling limit. Analysis of the results in figure three reveals the following:

- The lowest cost in the three scaling limit scenarios is the one with the minimum scalability limit. However, this will be at the expense of quick volume leveling performance. The tradeoff between cost and quick volume production leveling is well manifested in the decisions of the manufacturers concerning how much they are willing to invest in dynamic capacity scalability.

In addition, the cost performance of "average lean" policy and the "no lean" policy get closer to one another as the scalability limit decreases. The reduction of the capacity scalability reflects the system's ability to produce at takt time. The "average lean" policy implements many other lean mechanisms than the "no lean" policy, however, from a cost perspective, the impact of the capacity scalability as a lean mechanism outweighs other mechanisms in the pursuit of achieving production volume leveling.

\subsection{Impact of mix production leveling policy on production leveling implementation cost}

After exploring volume production leveling feasibility for the selected lean policies, mix production leveling feasibility is investigated. In a typical lean environment, the customer defines the sequence of delivery which is reflected in the mix production leveling. Lean culture promotes mix leveling to gain multiple benefits including shorter lead times, flexibility, less defect liability, smaller inventory and shorter order-to-cash time. A natural outcome of mix production leveling is smaller batch sizes. Mix leveling is typically measured by the Heijunka metric EPEx which stands for Every Part Every $x$ time period where $x$ represents the delay accepted by customer. In this model, the backlog cost function (Eq. (22)) was modified to include both the backlog penalty for quantity (volume) delay and a ramp up linear penalty function for mix delay. The ramp up function reflects, in a simple form, how customer dissatisfaction due to bad mix leveling policy increases with time. Better temporal modeling for customer mix leveling dissatisfaction should be investigated in further research; however, the ramp up assumed function is sufficient for the required analysis. Eq. (25) calculates the new backlog cost:

$C_{\mathrm{Blg}}(t)=\operatorname{Backlog}(t) * P_{\mathrm{Blg}}+P_{\text {mix }}(\operatorname{RAMP}(45,0,160))$

Fig. 5 compares the costs performance of the best lean policy with two delivery sequence scenarios. The desired customer delivery sequence is a batch of 1200 part/week for each of the two products. Two mix leveling policies are considered; one would produce 1200 parts/week of each part type and thus will include 4 change-over activities per month with 1 week late delivery to maintain the desired mix. The other will produce larger batches of 2400 for each product which will require 2 change-over activities per month with 2 weeks late delivery. From the figure, the mix leveling policy with 2 weeks delay has a better cost performance for the first two weeks and half (CRP at $t=100)$, and that performance is then reversed. This means that only for short period, given the considered costs and penalties, the leveling policy should consider larger batch sizes while from a cost perspective, smaller batch sizes
Graph for Total Cost

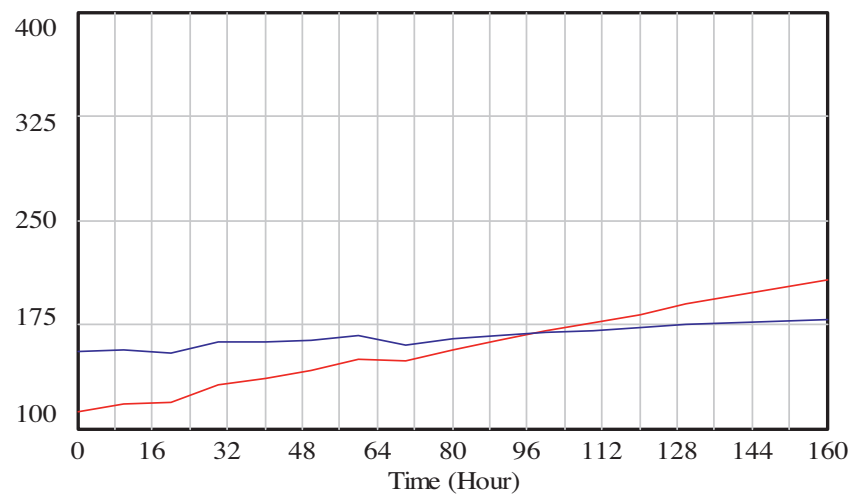

Total Cost : Leveling Policy 1 week delay w best lean Dollar

Total Cost : Leveling Policy 2 weeks delay w best lean Dollar

Fig. 5. Cost for production leveling with different delivery sequencing at best lean policy.

are better for mix production leveling. Different cost settings will lead to different CRP, however, the trade-off decision for batch size considering cost for multiple setups versus the penalty for mismatching desired customer sequence will remain a challenge for the dynamic mix production leveling in lean systems.

To examine the impact of SMED as a fundamental lean tool, together with the other considered lean tools, in achieving mix leveling the cost performance including sequence delivery penalty of both the no lean policy and the best lean policy are compared. The comparison is carried out for the two delivery sequencing scenarios mentioned earlier and results are shown in Fig. 6. Analysis of these results reveals that the "best lean" policy outperforms the "no lean" policy in both delivery sequencing scenarios except for the first week of the production period (CRP at $t=40$ ). This highlights the importance of investing in SMED as well as other lean tools to avoid penalties incurred for defaulting on the required sequencing delivery. This is, however, not recommended for very small lots in the considered cost settings (i.e. before CRP).

The impact of turbulent demand versus steady demand with the mix leveling policy requiring 4 changeovers on the overall cost dynamics is observed. The comparison is carried out between both best lean and no lean policies and the turbulence of the demand is adjusted through setting the standard deviation of the stochastic demand (SD) to be $50 \%$ of the required demand for turbulent demand case and $0 \%$ of the required demand for steady demand case. The results are displayed in Fig. 7 revealing the following:

- The demand turbulence increases the cost of production in both the best lean and the no lean policies scenarios. Turbulent demand increases production variability leading to more WIP and higher backlog level even with high level of lean implementation.

- The need for production leveling through lean mechanisms is well justified with turbulent demand. The cost performance difference for the no lean policy in the steady demand scenario is stable and much lower than the case for turbulent demand which is higher and has a continuous increase pattern. The ability of dynamic capacity, JIT tools and efficient SMED mechanisms to manage variation induced by demand turbulence is the main reason for that production cost reduction.

Unlike all previous analyses, the impact of different capacity scalability limits at low and high product mix leveling policies on the accumulated WIP level rather than cost will be considered next. The objective is to gain an insight into the behavior of an 


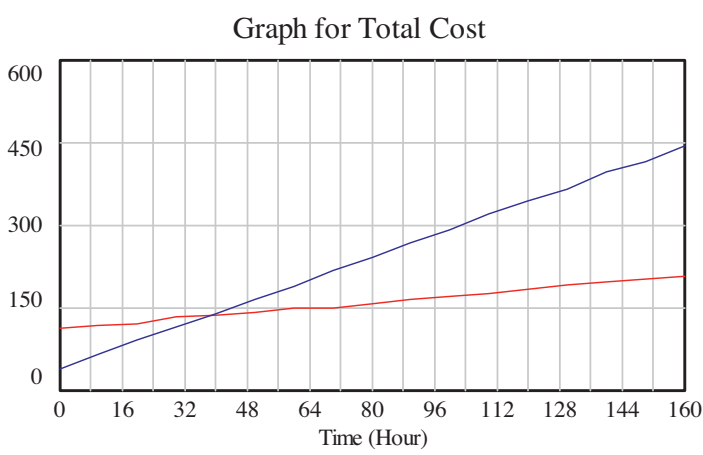

Total Cost : Leveling Policy 2 weeks delay w no lean Total Cost : Leveling Policy 2 weeks delay w best lean

(a)

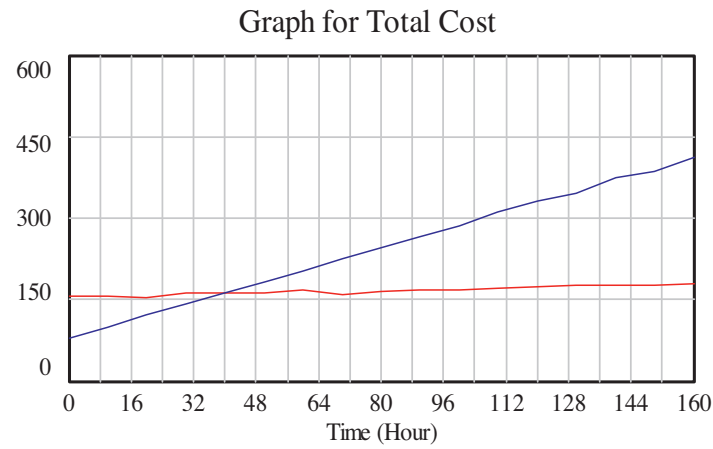

Total Cost : Leveling Policy 1 week delay w no lean Dollar Total Cost : Leveling Policy 1 week delay w best lean _ Dollar

(b)

Fig. 6. Cost performance comparison for no lean policy and best lean policy at (a) 2 weeks sequencing delay and (b) 1 week sequencing delay.

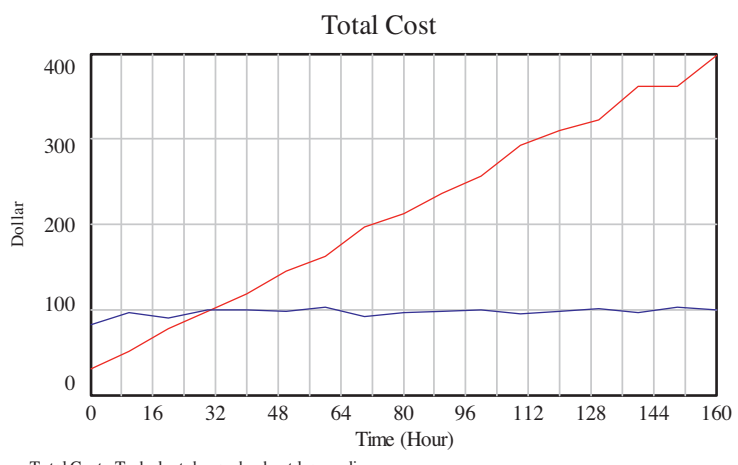

Total Cost : Turbulent demand w best lean policy

(a)

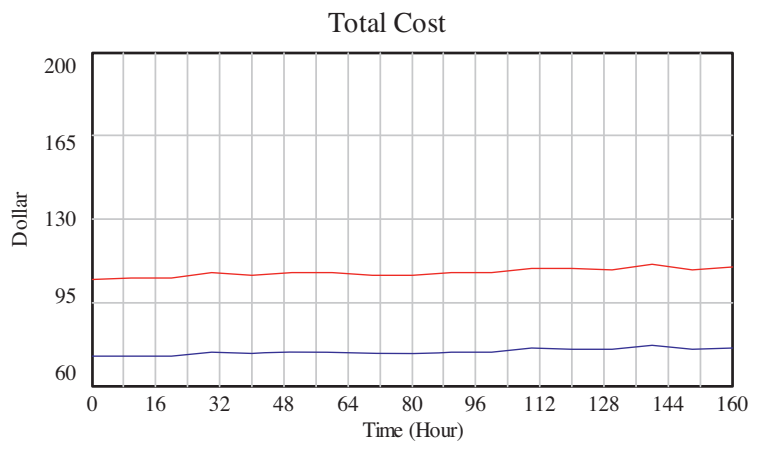

Total Cost : Steady demand w best lean policy Total Cost : Steady demand w no lean policy

(b)

Fig. 7. Cost performance comparison for no lean policy and best lean policy at (a) turbulent demand and (b) steady demand.

important internal system aspects while considering the two production leveling approaches - these are volume leveling through capacity scalability and mix leveling through different delivery sequencing scenarios. Furthermore, the accumulated WIP level has a direct impact on the producer cost as explained earlier. Fig. 8 displays the accumulated WIP at different capacity scaling levels (expressed as percentage of the normal available capacity) for two mix leveling scenarios. The first is for a delivery sequence of batches of size 300 for each product which will include 16 changeovers per month and this scenario is referred to as high mix leveling policy.
Total WIP

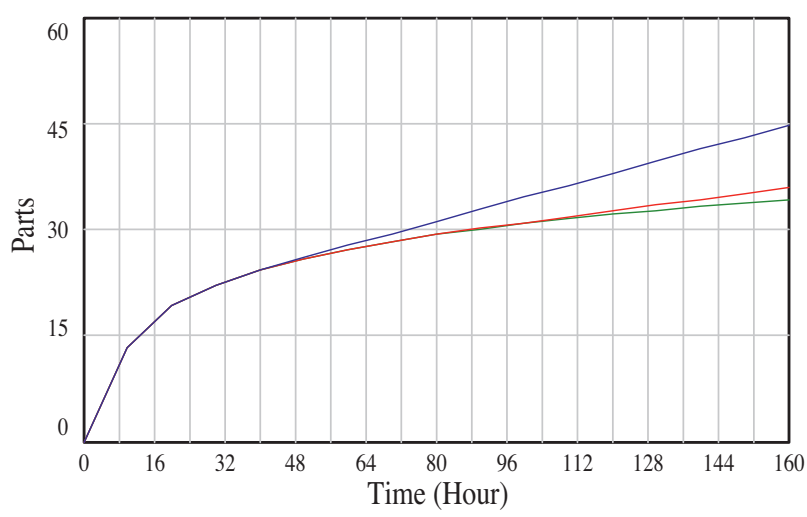

Total WIP : cap avail 10 percent Total WIP : cap avail 20 percent

Total WIP : cap avail 40 percent

(a)

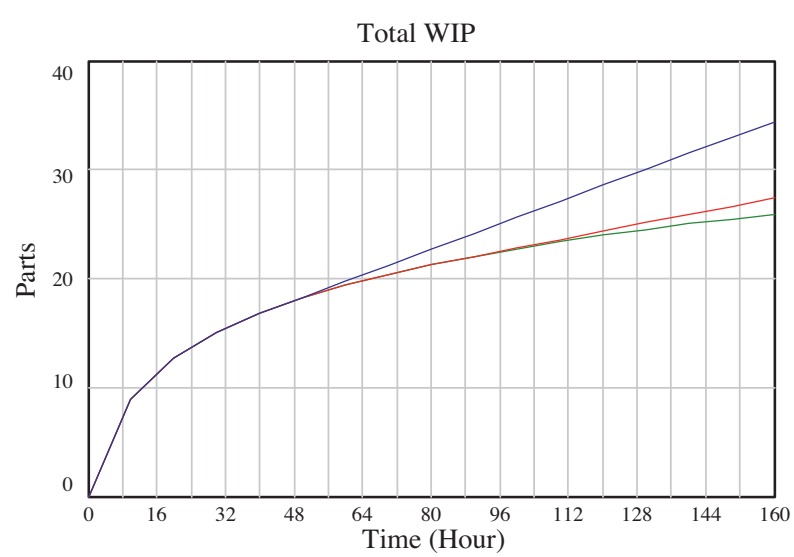

Total WIP : cap avail 10 percent Total WIP : cap avail 20 percent Total WIP : cap avail 40 percent

\section{(b)}

Fig. 8. WIP level performance comparison for different capacity scalability levels at (a) high mix leveling policy and (b) low mix leveling policy. 
The second scenario is for the batch size of 1200 which require 4 changeovers per month and referred to as low mix leveling policy. The analysis is carried out at the best lean policy settings. Investigating Fig. 7 reveals the following:

- The WIP accumulation levels in both scenarios show similar behavior at different capacity scalability levels for a certain production period (around 30\% of the considered period) before they differentiate. This highlights the importance of caution with regard to the decision of how much to invest in capacity scaling relative to the planned production period (and thus the batch size). With smaller production periods, in the given settings, lower capacity scalability options will perform exactly the same as higher scaling options considering WIP level as a performance index.

- As expected, the accumulated WIP level at high mix leveling policy is higher than that at the low mix leveling one. Aligning the system with high degree of market variation reflected in mix leveling always has its negative impact on the system internal stability which requires a well-planned tradeoff between responsiveness level and internal production stability. This will also have its impact on the decision for the degree and cost of SMED and other lean tools that can decrease the time required for multiple change over activities.

- Capacity scalability continues to show a positive effect on managing volume leveling as well as reducing the accumulated WIP level. This is shown with the decrease of the WIP level as the scaling percentage increase. It is important to note that this is also due to the capacity scalability policy adopted in this model which takes into account the required volume leveling objective as well as accumulated WIP and backlog as explained in Eq. (8).

\section{Conclusions and recommendations}

The main objective of the proposed work was to develop a system dynamics model as a decision support system to monitor and evaluate the cost of considered lean production leveling policies. The novelty of the proposed model is in capturing both the parts volume and parts mix production leveling policies (not only one of them) while considering cost dynamics as the main performance metric in evaluating various (not only single) lean tools implementation. The production leveling policy was integrated into the model through various lean tools including SMED, JIT, TPM, mix sequencing and scalable capacity. The costs associated with implementing these tools were captured based on activity based costing (ABC) together with the costs incurred due to the system's accumulated backlog and WIP to account for the overall feasibility of the lean policies implementing production leveling. The main conclusions and recommendations revealed by the presented analysis of the considered case study and cost settings are summarized as follows:

- Successful production leveling should not be considered based only on its positive impact on the system's behavior. The presented dynamic cost analysis showed that such leveling comes at a cost that should be well-assessed.

- Feasible implementation of production leveling as a lean principle is closely related to cost-efficient capacity scalability. Results showed that costly production capacity scaling can render lean polices which implement production leveling (Heijunka) difficult to justify from a cost perspective. In addition, capacity scaling constraints affect the lean planner's choice of lean policies considering the required tools and the cost of implementing them in order to maintain successful production leveling.

- Lot size selection was demonstrated to be influential in choosing a feasible lean policy for production leveling implementation both in terms of products mix and products volume. The lot size choice requires a trade-off between cost and responsiveness as well as cost and flexibility. The developed system dynamics model can facilitate such decision due to its ability to capture different lean policies and their associated costs.

- Demand turbulence highlights the importance of lean production leveling polices due to the ability of lean tools to reduce the variability induced by such turbulence on the system. Lean production leveling polices were shown to be better justified in turbulent demand than in steady demand environments due to the system's improved cost performance.

- Considering the accumulated WIP level as an influential parameter in production leveling feasibility impacts the decision to adopt mix leveling policy for the market as well as the required investment in capacity scalability.

This research demonstrated that the benefits gained by implementing lean policies in manufacturing systems depend on many system and market related factors. The choice between the "best lean" and "no lean" policies for achieving production leveling does not have to be strictly binary, however; instead it can be seen as a continuum between these two extremes. An appropriate policy and implementation level should be carefully tailored for a given system and market conditions. While implementing lean manufacturing policies is desirable it should not be achieved at any cost. The presented system dynamics model provides support for decision makers and helps explore many what-If scenarios and associated costs and benefits.

\section{References}

[1] Rother M, Shook J. Learning to see. Cambridge, MA: The Lean Enterprise Institute; 2003

[2] Wan $\mathrm{H}$, Chen F. A leanness measure of manufacturing systems for quantifying impacts of lean initiatives. Int J Prod Res 2008;46(23):6567-84.

[3] Hines P, Holweg M, Rich N. Learning to evolve: a review of contemporary lean thinking. Int J Oper Prod ManageV 24 2004;(10):994-1011.

[4] Shah R, Ward P. Defining and developing of lean production. J Oper Manage 2007;25:785-805

[5] Holweg M. The genealogy of lean production. J Oper Manage 2007:25(2):420-37

[6] Moyano-Fuentes J, Sacristan-Diaz M. Learning on lean: a review of thinking and research. Int J Oper Prod Manage 2012;32(5):551-82.

[7] Amin M, Karim MA. A time-based quantitative approach for selecting lean strategies for manufacturing organizations. Int J Prod Res 2013;51(4):1146-67.

[8] Cheah ACH, Wong W, Deng Q. Challenges of lean manufacturing implementation: a hierarchical model. In: Proceedings of the 3rd 2012 international conference on industrial engineering and operations management. 2012. p. 2091-9

[9] Kodua K, Ajaefobi J, Weston R. Modeling dynamic value streams in support of process design and evaluation. Int J Comput Integr Manuf 2009;22(5):411-27.

[10] Black T. Design rules for implementing the Toyota production systems. Int J Prod Res 2007;45(16):3639-64.

[11] Cochran S, Eversheim W, Kubic G, Sesterhenn L. The application of axiomatic design and lean management principles in the scope of production system segmentation. Int J Prod Res 2000;38(6):1377-96.

[12] Detty R, Yingling J. Quantifying benefits of conversion to lean manufacturing with discrete event simulation: a case study. Int J Prod Res 2000;38(2):429-45.

[13] Welgama S, Mills J. Use of simulation in the design of a JIT system. Int J Oper Prod Manage 1995;15:245-60.

[14] Savasar M, Al-Jawini A. Simulation analysis of just in time production systems Int J Prod Econ 1995;42:67-78.

[15] Lian Y, Van Landeghem H. Analysing the effects of lean manufacturing using a value stream mapping-based simulation generator. Int J Prod Res 2007;45(13):3037-58.

[16] Diaz-Elsayed N, Jondral A, Grienacjer S, Dornfeld D, Lanza G. Assessment of lean and green strategies by simulation of manufacturing systems in discrete production environment. CIRP Ann - Manuf Technol 2013;62:475-8.

[17] Monden Y. Toyota production system. Norcross, GA: Industrial Engineering and Management Press, Institute of Industrial Engineers; 1983.

[18] De Smet R, Gelders L. Using simulation to evaluate the introduction of a kanban subsystem within an MRP-controlled manufacturing environment. Int J Prod Econ 1998;56-57:111-22

[19] Browning R, Heath D. Re-conceptualizing the effects of lean on production costs with evidence from the F-22 program. J Oper Manage 2008;24:203-18. 
[20] Huttmeir A, Treville S, Ackere A, Monnier L, Prenninger J. Trading off between Heijunka and just-in-sequence. Int J Prod Econ 2009;118:501-7.

[21] Deif A. Dynamic analysis of a lean cell under uncertainty. Int J Prod Res 2012:50(4):1127-39.

[22] Khataie A, Bulgak A. A cost of quality decision support model for lean manufacturing: activity-based costing application. Int J Qual Reliab Manage 2013;30(7):751-64.

[23] Lopez P, Arbos A. Lean manufacturing: costing the value stream. Ind Manage Data Syst 2013;113(5):647-68.

[24] Meade D, Kumar S, Houshyar A. Financial analysis of a theoretical lean manufacturing implementation using hybrid simulation modeling. J Manuf Syst 2006;25(2):137-52

[25] Modarress B, Ansari A, Lockwood D. Kaizen costing for lean manufacturing: case study. Int J Prod Res 2013:43(9):1751-60.

[26] Rivera L, Chen F. Measuring the impact of lean tools on the cost time investment of a product using cost-time profiles. Int J Prod Econ 2007;23:684-9.

[27] Sterman J. Modeling complex world. NY: McGraw-Hill; 2000.
[28] Huh WT, Roundy RO, Cakanyildirim M. A general strategic capacity planning model under demand uncertainty. Nav Res Log 2006;2:137-50.

[29] Deif A, ElMaraghy H. Modeling and analysis of dynamic capacity complexity in multi-stage production. J Prod Plann Contr 2009;20(8):737-49.

[30] Putnik C, Sluga A, ElMaraghy H, Teti R, Koren Y, Tolio T, et al. Scalability in manufacturing systems design and operation: state-of-the-art and future developments roadmap. CIRP Ann - Manuf Technol 2013;63(Kn): $1-24$.

[31] Cooper R, Kaplan S. The design of cost management systems: text, cases and readings. Englewood Cliffs, NJ: Prentice-Hall; 1991.

[32] Cooper R. Activity-based management and the lean enterprise. J Cost Manage 1996;9(4):6-14

[33] Johnson HT. Activity based information: a blueprint for world-class management accounting. Manage Account 1988;(June):23-30.

[34] ElMaraghy H. Flexible and reconfigurable manufacturing systems paradigms. Int J Flex Manuf Syst 2005;17(4):261-76 [Special issue on Reconfigurable Manufacturing Systems]. 